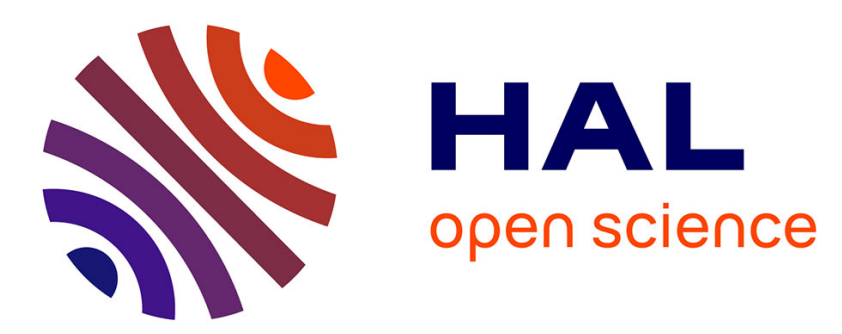

\title{
Double introduction of highly pathogenic H5N1 avian influenza virus into France in early 2006
}

Ghislaine Le Gall-Recule, François-Xavier Briand, Audrey Schmitz, Olivier

Guionie, Pascale Massin, Véronique Jestin

\section{- To cite this version:}

Ghislaine Le Gall-Recule, François-Xavier Briand, Audrey Schmitz, Olivier Guionie, Pascale Massin, et al.. Double introduction of highly pathogenic H5N1 avian influenza virus into France in early 2006. Avian Pathology, 2008, 37 (01), pp.15-23. 10.1080/03079450701774835 . hal-00540102

\section{HAL Id: hal-00540102 \\ https://hal.science/hal-00540102}

Submitted on 26 Nov 2010

HAL is a multi-disciplinary open access archive for the deposit and dissemination of scientific research documents, whether they are published or not. The documents may come from teaching and research institutions in France or abroad, or from public or private research centers.
L'archive ouverte pluridisciplinaire HAL, est destinée au dépôt et à la diffusion de documents scientifiques de niveau recherche, publiés ou non, émanant des établissements d'enseignement et de recherche français ou étrangers, des laboratoires publics ou privés. 


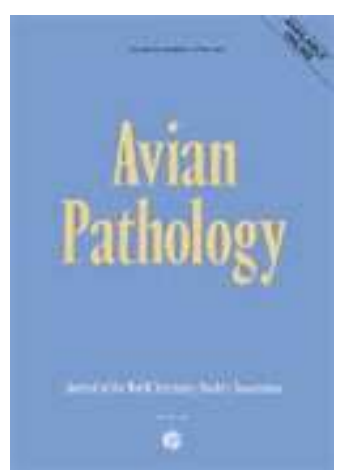

\section{Double introduction of highly pathogenic H5N1 avian influenza virus into France in early 2006}

\begin{tabular}{|c|c|}
\hline Journal: & Avian Pathology \\
\hline Manuscript ID: & CAVP-2007-0087.R2 \\
\hline Manuscript Type: & Original Research Paper \\
\hline $\begin{array}{r}\text { Date Submitted by the } \\
\text { Author: }\end{array}$ & 12-Sep-2007 \\
\hline Complete List of Authors: & $\begin{array}{l}\text { Le Gall-Recule, Ghislaine; AFSSA, UVIPAC } \\
\text { Briand, François-Xavier; AFSSA, UVIPAC } \\
\text { Schmitz, Audrey; AFSSA, UVIPAC } \\
\text { Guionie, Olivier; AFSSA, UVIPAC } \\
\text { Massin, Pascale; AFSSA, UVIPAC } \\
\text { Jestin, Véronique; AFSSA, UVIPAC }\end{array}$ \\
\hline Keywords: & Avian influenza virus, HPAIV, H5N1, molecular epidemiology \\
\hline
\end{tabular}

\section{SCHOLARONE Manuscripts}




\section{Cavp-2007-0087.R2}

Formatted: Font: Not Bold

Double introduction of highly pathogenic H5N1 avian influenza virus into

France in early 2006

Ghislaine Le Gall-Reculé*, François-Xavier Briand, Audrey Schmitz, Olivier

Guionie, Pascale Massin and Véronique Jestin.

French Agency for Food Safety (AFSSA), Avian and Rabbit Virology, Immunology and

Parasitology Unit, French Reference Laboratory for Avian Influenza and Newcastle

Disease, B.P. 53, 22440 Ploufragan, France.

Running title: Double introduction of H5N1 HPAIV in France

Tel: +33 (2) 96016298

Fax: +33 (2) 96016263

e-mail address: g.legall@ ploufragan.afssa.fr

Received: 21 May 2007 


\section{Cavp-2007-0087.R2}

\section{Double introduction of highly pathogenic H5N1 avian influenza virus into}

\section{France in early 2006}

\section{Ghislaine Le Gall-Reculé*, François-Xavier Briand, Audrey Schmitz, Olivier}

\section{Guionie, Pascale Massin and Véronique Jestin.}

\section{Abstract}

Highly pathogenic avian influenza (HPAI) viruses of subtype H5N1 have spread since late 2003 in East and Southeast Asia. In April 2005, a large-scale outbreak of H5N1 infection that occurred in migratory waterfowl in Qinghai Lake nature reserve in western China killing more than 6,000 wild birds, appeared to be the beginning of a epizootic that caused outbreaks in domestic and wild birds in nearly 60 countries from Central Asia, the Middle East, Europe and Africa. The first case of Asian lineage HPAI H5N1 virus in France was described in dead wild ducks (Common pochard) in the east of France in mid-February 2006. Up to the end of April, 42 HPAI H5N1 viruses were identified from about 60 wild birds belonging to different species and one outbreak occurred in commercial turkeys. To establish genetic relationships with other HPAI H5N1 viruses, twelve selected viruses were subjected to phylogenetic analysis.

Genotyping and genetic analyses revealed that the French viruses were very similar to those of the 'Qinghai-like' sublineage and belonged to clade 2.2. However, two related but distinct genetic subgroups were identified, indicating that two different viruses were circulating in France at the same time and in the same area. Viruses of one subgroup were highly similar to one identified in Bavaria in Germany 
(A/mallard/Bavaria/1/2006). More surprisingly, French viruses belonging to the other Deleted: subgroup retained the cleavage motif PQGERKRKKR/G, which is unique among the known HPAI H5N1 viruses. Our results confirmed that multiple H5N1 genogroups were present in Western Europe in early 2006. 


\section{Introduction}

Highly pathogenic avian influenza (HPAI) virus of subtype H5N1 was initially isolated from farmed geese in Guangdong Province in southern China in 1996

(A/goose/Guangdong/1/96 virus) (Xu et al., 1999), where it caused about 40\%

mortality. Subsequently, different reassortants of this precursor with other AI viruses emerged from goose and duck reservoirs (Webster et al., 2002) generating multiple genotypes that caused outbreaks in southeast China (Chen et al., 2006b; Guan et al., 2002; Li et al., 2004). Genotypes from 2002 were antigenically distinguishable from the earlier H5N1 strains and biologically much more pathogenic for waterfowl and wild birds (Ellis et al., 2004; Kishida et al., 2005; Sturm-Raminez et al., 2004). By late 2003, the H5N1 virus spread outside China to affect poultry in East and Southeast Asia.

During 2004, it became enzootic in several Asian countries (Li et al., 2004), resulting in depopulation of millions of birds (Webster et al., 2006). In addition there were fatal infections in mammals notably felids (Keawcharoen et al., 2004; Kuiken et al., 2004) and humans (Peiris et al., 2004; Tran et al., 2004). In May 2005 a large-scale outbreak of H5N1 infection occurred in migratory waterfowl in Qinghai Lake natural reserve in north-western China resulting in the death of more than 6,000 wild birds, mainly barheaded geese (Anser indicus). The H5N1 viruses isolated were closely related to viruses found previously in poultry in southern China (Chen et al., 2005), suggesting a link to the Qinghai outbreak. Several genotypes were identified but the geographical distribution one genotype expanded (Chen et al., 2005) and caused outbreaks in domestic or wild birds in nearly 60 countries from Central Asia, the Middle East, Europe and Africa. Simultaneously, a marked increase in countries reporting human infection cases was observed. In Europe, several countries first reported H5N1 
infections between February and March 2006, primarily in mute swans Cygnus olor, (day and month of the discovery of H5N1 infected birds): Greece (30/01), Bulgaria (31/01), Italy (01/02), Hungary (04/02), Germany (08/02), Slovenia (11/02), Austria (13/02), France (13/02), Albania (16/02), Bosnia-Herzegovina (16/02), Slovakia (17/02), Sweden (24/02), Switzerland (26/02), Serbia-Montenegro (28/02), Poland (02/03), Denmark (/03), Czech Republic (20/03), and United Kingdom (30/03) (data from OIE, 2006a).

The first case of HPAI virus of subtype H5N1 in France was identified using Formatted: Left, Indent: First line: standard international procedures (Alexander, 2005) in mid-February 2006 in dead wild ducks (Aythya farina, Common pochard) in the French eastern department of Ain (La Dombes area) (OIE, 2006b). Up to mid-April, several HPAI H5N1 viruses were described in 42 cases involving more than 60 wild birds (predominantly mute swans), and a single outbreak in commercial turkeys (OIE, 2006c). This holding was located 1 $\mathrm{km}$ from where the index case virus was found one week earlier, and the origin of Deleted: before infection was related to the virus circulating in wild birds. Sanitary measures were taken to avoid the propagation of the infection and no other French commercial holding was infected after this outbreak. All the cases were detected within the La Dombes area where a multitude of lakes and ponds are present, except for two viruses identified near the Switzerland border and one virus identified in the south of France. The partial sequence of the H5 and N1 genes of the index case and the turkey outbreak were made available to the scientific community (Genbank Accession numbers: AM231714, AM231713, AM236074 and AM236075, respectively) and the identification was further confirmed by the Community Reference Laboratory, Weybridge, United Kingdom (OIE, 2006b). 
To learn more about these French HPAI viruses and to establish genetic relationships with other HPAI H5N1 viruses, twelve viruses were selected and all eight gene segments of each virus were partially sequenced and compared in order to Deleted: according to the species, area, the date of collection, and preliminary results obtained following phylogenetic analyses achieved on the partial $\mathrm{H} 5$ and $\mathrm{N} 1$ gene sequences. All

determine their host origin and virus genotype.

Deleted: genotyping

Formatted: Left

\section{Materials and Methods}

Virus selection. Between mid-February and mid-April 2006, 41 HPAI H5N1 cases

were reported in one department in the east of France (Ain, in La Dombes area,

essentially) and one case in the south of France (Bouche-du-Rhône, in Camargue area),

involving more than 60 wild birds (Figure 1) since, in some occasions, pools of samples

Deleted: in fact were analysed. In addition, one outbreak was observed in a commercial turkey holding

(Figure 1). Among the 43 HPAI H5N1 viruses identified, twelve were selected in order to acquire more detailed genetic information. The selection criteria were the bird species involved, the area where the birds were obtained, the date of collection and the

Deleted: and

Deleted:

preliminary results that we obtained following phylogenetic analyses on partial H5 and

N1 gene sequences (Le Gall-Reculé et al., 2006). Thus, jn addition to the index case

Deleted: besides

virus obtained from a common pochard in mid-February 2006 and the virus identified

Deleted: identified in one week later in commercial turkeys in the same area, the 10 viruses detailed in Table 1 were subjected to analyses.

Deleted: II

RNA extraction and virus isolation. RNA was extracted from either tracheal and

Formatted: Left cloacal swabs according to European standardized procedures (Alexander, 2005). For

six viruses, including the index case, the virus from turkeys, and four other viruses (in

Deleted: included 
bold in Table 1), the virus from tracheal or cloacal samples were grown in 9-day-old

embryonated specific-pathogen-free (SPF) fowls' eggs following standard procedures

(Alexander, 2005). If necessary, two passages were performed to increase the viral titre.

Viral RNA was extracted from infective allantoic fluid according to standard procedures

(Alexander, 2005). All the manipulations of live viruses were performed in a biosafety

level 3 (BSL-3) containment facility.

Genetic and phylogenetic analyses. Viral RNA were reverse transcribed using

hexanucleotides as primers. cDNAs were subjected to PCR using fragment-specific primers (primer sequences available upon request) and a high fidelity DNA polymerase (Platinum ${ }^{\circledR}$ Taq DNA Polymerase High Fidelity, Invitrogen). For viruses that appear in bold in Table 1, full-length cDNA derived from the $\mathrm{H} 5$ gene segment were amplified by PCR using H5 specific primers (primer sequences kindly provided by M. L. Perdue, WHO, Geneva, Switzerland; formally USDA, Athens, Georgia, USA). For N1, three overlapping PCRs were finalized and the final NA nucleotide sequence studied was 116-1056. The nucleotide sequence from HA and NA segments of the six other viruses were 933-1176 and 116-698, respectively. The nucleotide sequences from the other gene segments of the twelve H5N1 viruses were as follows: PB2 69-402 and 15792243, PB1 84-265, PA 69-510, NP 675-1341, M 36-702, NS 49-486. All amplified PCR products were visualised by electrophoresis on agarose gel and purified (MinElute ${ }^{\mathrm{TM}}$ Gel extraction kit, Qiagen) prior to sequencing. The DNA sequence was determined by sequencing in both senses by the dye terminator method (ABI PRISM DyeTerminator Cycle Sequencing Ready Reaction Kit, Applied Biosystems) on an automatic DNA sequencer ABI 373XL (Applied Biosystems) with the PCR primers. 
The host origin of all eight gene segments was determined by BLAST search on

viral nucleotide sequences available from the National Center for Biotechnology

Information, Bethesda, Md. (http://www.ncbi.nlm.nih.gov) and confirmed by

phylogenetic analyses performed with representative avian, porcine, and human

influenza virus A sequences. For genotyping, each gene segment sequence was analysed together with HPAI H5N1 virus sequence data obtained from the Influenza Sequence Database (Macken et al., 2001) (http://apollo.lanl.gov) representative of some earlier genotypes (genotypes B and C) including one of the ancestor virus

(A/goose/Guangdong/1/96), and some more recent genotypes (Z, Z+, V, G, W, VTM, Qinghai-like, FJ-like), according to Li et al. (2004), Chen et al. (2006b), and Smith et al. (2006).

Phylogenetic analyses were conducted using MEGA version 3.1 software (Kumar et al., 2004) for phenetic (Neighbor-joining) and cladistic methods, and using PHYLIP version 3.6 (Felsenstein, 2002) for maximum likelihood method. Multiple sequence alignments were generated by the CLUSTALW method (Thompson et al., 1994). Gaps introduced by NA stalk and NS deletions were removed in order to eliminate this bias. For phenetic analysis, the Neighbor-joining algorithm was implemented with Kimura-2 parameters model using a transition-to-translation ratio of 2.0. Topology of trees was evaluated by 1,000 bootstrap analyses. Majority-rule consensus trees were determined by the CONSENSE program and were drawn using MEGA version 3.1 software. The deduced amino acid sequences were generated using the software available on the Biosupport web site (http://www.bioinfo.hku.hk) and amino acid multiple sequence alignments were analysed using the NPS web site (http://npsa-pbil.ibcp.fr).

Formatted: Left 
Nucleotide sequence accession numbers. Nucleotide sequences analysed in this study and used in the published phylogenetic trees are available in databases under accession numbers EF395820 and EF395821 (HA and NA sequence of A/mute swan/06299/2006, respectively), AM49605 to AM498616 for PB1 partial sequences, AM498617 to AM498627 for NA partial sequences and AM498628 to AM498632 for HA sequences.

\section{Results}

Phylogenetic analysis. Twelve French H5N1 viruses were characterised genetically and partial sequences of each gene segment were first determined. Results of BLAST search on viral nucleotide sequences available in databases were confirmed by phylogenetic analyses performed with representative avian, porcine, and human influenza virus A sequences. They revealed that all the 8 genomic segments from the French isolates studied in this work were of avian origin. Genotyping of each French virus was also established. The phylogenetic trees of the PB2, PB1, PA, M and NS were similar to one another (represented by the PB1 gene, Figure 2) and revealed that these genes were closely related to their counterparts of the genotype Z H5N1 viruses A/chicken/Shantou/810/2005, A/goose/Shantou/2216/2005, and A/feral pigeon/Hong Kong/862.7/2002 (Chen et al., 2005; Liu et al., 2005). In contrast, the phylogenetic trees of the HA, NA and NP genes of the French viruses also similar to one another, revealed that these genes were closely related to the genotype V H5N1 viruses A/migratory duck/Jiangxi/2136/25/2004, A/chicken/Shantou/4231/2003, A/chicken/Yamaguchi/7/2004, and A/chicken/Korea/ES/2003 (Chen et al., 2006c; Liu et al., 2005; Mase et al., 2005). 
The entire H5 (1707 bp) and $70 \%$ N1 (941 bp) sequences were obtained for six

viruses. Phylogenetic relationships of these two genes were established by comparison with some earlier genotypes including the A/goose/Guangdong/1/96 virus, the representative Asian H5N1 strains collected during 1999-2006 and the available 20052006 H5N1 sequences from western Asia (China, Mongolia), Russia (Novosibirsk, Kurgan, Astrakhan), Middle East (Turkey, Iraq), Africa (Egypt, Nigeria), and Europe (Italy, Germany and Ukraine). According to these nucleotide sequences, analyses were based on nucleotides 77-1631 of the HA gene and 116-1041 of the NA gene. Majorityrule consensus trees constructed by the phenetic, cladistic and maximum likelihood methods yielded similar topologies.

Phylogenetic analyses confirmed that HA (Figure 3) and NA (data not shown) genes had originated from the A/Goose/Guandong/1/96-like lineage (94.9 and $95.2 \%$ nucleotide homology, respectively). HA genes of the French isolates belonged to a significant cluster (100\% bootstrap value) branched with A/great-headed gull/Qinghai/1/2005 virus and that included viruses isolated in 2004-2005 in China (notably one isolate belonging to genotype V) and in 2005-2006 in Russia, Turkey, Iraq, Africa, and Europe (Figure 3). The maximum nucleotide divergence was $1.4 \%$. The HA tree also revealed that the French isolates were significantly closer (78 \% bootstrap value) to viruses isolated in Egypt, Turkey, Slovenia, Italy (A/mallard/Italy/835/2006), Germany (A/common bussard/Bavaria/2/2006 and A/mallard/Bavaria/1/2006), and Czech Republic (1.2\% maximum divergence occurred between all of these viruses). The phylogenetic tree obtained with NA genes revealed an almost similar topology. Moreover, in the H5 and N1 phylogenetic trees the six French isolates clustered

Deleted: showed that $\mid$ into two different subgroups. For HA genes, the first subgroup (06167-2.1 and 06303 viruses) was significantly clustered (bootstrap value: $91 \%$ ) with viruses identified in 
Egypt, Turkey, Slovenia, Italy (A/mallard/Italy/835/2006), Germany (A/common bussard/Bavaria/2/2006), and Czech Republic. The second subgroup was clearly identified (bootstrap value: 99\%) and grouped together the other four viruses and the A/mallard/Bavaria/1/2006 virus. French HA sequences within each subgroup were very similar (99.8-99.9\% nucleotide sequence similarity), whereas these values reached 98.999.3\% between the two subgroups. Although the NA phylogenetic tree yielded two similar subgroups, only the second one was supported by a significant bootstrap value (94\%). When we compared the NA gene sequences, the two isolates from the first subgroup were identical and the four isolates from the second subgroup shared a high homology with each other (99.8-100\% nucleotide sequence similarity), whereas the nucleotide similarities between the two subgroups were 99-99.1\%. In addition, French isolates belonging to the second subgroup were very close to the $\mathrm{A} /$ mallard/Bavaria/1/2006 virus (99.8-99.9\% HA nucleotide sequence similarity and 99.6-99.8\% NA nucleotide sequence similarity).

Distribution of the six French H5N1 viruses into two subgroups agreed with the tendency observed when phylogenetic analyses were performed using the partial nucleotide sequence of each 8-gene segment from the twelve French viruses.

Formatted: Left

Molecular characterisation. The molecular characteristics of the French viruses that we obtained in this study are reported in Table 2. All the twelve viruses maintained the Deleted: were motif of multiple basic amino acids at the HA cleavage site characteristic of HPAI. However, 3 viruses (06167-2.1, 06303, and 06254a) showed a different amino acid residue and retained the motif PQGERKRKKR/G. Unlike the other two viruses, this motif was found only in a part of the index case viral RNA population, the other part 
maintaining the PQGERRRKKR/G motif (Accession number AM231714). According to phylogenetic results mentioned above, the 3 viruses belonged to the same subgroup. Achievement of entire HA sequences for six viruses isolated into eggs allowed Formatted: Left, Indent: First line: $36 \mathrm{pt}$ us to acquire more information on this gene. The receptor binding pocket of HA1 retained amino acid residues Q 222 and G 224 (positions 226 and 228 in H3 numbering, positions 238 and 240 when numbered from the H5 ATG; this numbering is used throughout) that preferentially bind to 2,3-NeuAcGal linkages of avian cell-surface receptors (Ha et al., 2001). We identified the two substitutions (A99I and Y268N) that seemed to be unique to viruses isolated from migratory birds at Qinghai Lake (Chen et al., 2006b) and the presence of the R to G mutation at position -8 of the HA1 connecting peptide. This last mutation was observed in a few viruses isolated from migratory ducks in Jiangxi in 2005 and in all isolates from Qinghai Lake (Chen et al., Deleted: 2006b). Moreover, there was no S145L or A172T substitution (positions 129 and 156 in H3 numbering) even in the turkey isolate (06222-1.1), these changes are commonly associated with viral adaptation to terrestrial poultry and increased virulence for these birds (Perdue \& Suarez, 2000).

Sequence analysis of the NA gene showed that the French viruses had a 20amino-acid deletions in the stalk of the molecule (aa 49 to 68) and had an arginine residue at position 110 as observed in viruses from Qinghai Lake (Chen et al., 2006b). Concerning the internal protein genes, there was a E627K mutation in the PB2 gene which has been associated with increased virulence of $\mathrm{H} 5 \mathrm{~N} 1$ viruses in mice (Hatta et al., 2001; Shinya et al., 2004) and of H7N7 viruses in humans (Fouchier et al., 2004). However, the host-dependent mutation D701N considered necessary to enable Deleted: sufficient replication and virulence in mice (Li et al., 2005) was not observed. The NS gene tree showed that the French viruses belong to clade A, in contrast to the ancestor virus 
A/goose/Guandong/1/96 virus and viruses isolated from a goose and a duck in Hong Kong in 2000 that belonged to clade B, NS1 genes showed the 5-amino-acid deletion (aa 80 to 84 ), which has been observed in Asian lineage HPAI H5N1 isolates since 2000 (except for $\mathrm{X}_{0}-\mathrm{X}_{3}$ genotypes) and that is known to confer some resistance to the antiviral effects of interferon and tumour necrosis factor produced by the host (Seo et $a l .$, 2002). No French viruses had the D92E substitution, which confers virulence and resistance to antiviral cytokines in pigs (Seo et al., 2002), but they had an alanine residue at position 144 (V144A, numbering including the deletion), which plays a role in the ability of the virus to antagonize the antiviral IFN response produced by host cell (Li et al., 2006). Concerning the M2 protein, no $\mathrm{S} 31 \mathrm{~N}$ substitution that invariably confers resistance to amantadanes (amantadine and rimantadine) was observed (Scholtissek et al., 1998). Sequence analysis revealed that the French isolates should be sensitive to these antiviral drugs. Moreover, we did not observe S64A and Q66A substitutions seen in genotype $\mathrm{Z}$ and $\mathrm{Z}+$ viruses from some highly pathogenic avian influenza H5N1 viruses isolated in Hong Kong in 2002-2003, in Thailand and Vietnam in 2003-2004 (Li et al., 2004). However, the biological role of these mutations is still unclear.

\section{Discussion}

The present study constitutes the first report on the characteristics of HPAI H5N1 viruses in France. Genotyping and genetic analyses revealed that the French viruses were very similar from those designated as 'Qinghai-like' sublineage viruses (Smith $e t$ al., 2006). Indeed, several characteristics were found in the French viruses identical to
} 
those of this sublineage. Firstly, 5- and 20-amino-acid deletions in NS and NA genes, respectively; secondly, HA, NA and NP genes were closely related to those of genotype $\mathrm{V}$ viruses, whereas the other five genes were closely related to those of genotype $\mathrm{Z}$ viruses; thirdly, deduced amino acid sequence at the cleavage site presented an $\mathrm{R}$ to $\mathrm{G}$ substitution at position -8 (PQGERRRKKR/G); fourthly, identification of two HA residues (I-99 and N-268) and one NA residue (R-110) that were shared by the 'Qinghai-like' viruses; and finally, an E627K substitution in the PB2 gene that increased virulence (Chen et al., 2005; Chen et al., 2006a; Li et al., 2006; Liu et al., 2005; Smith et al., 2006).

Chen et al. (2006a) reported four different introductions of H5N1 genotypes Formatted: Left, Indent: First line: $36 \mathrm{pt}$ (called by the authors genotypes 'A' to 'D') at the beginning of the Qinghai Lake outbreak based on PB2 gene differences. The authors demonstrated that genotype 'C' (with no link with the former genotype C reported in 2001 (Guan et al., 2002; Hatta et al., 2001)) found in multiple species was responsible for the wild bird outbreak of H5N1 infection notably in Mongolia and Russia during summer 2005. In July 2005, an H5N1 outbreak was described in domestic poultry in a village of Suzdalka in Russia (Novosibirsk region, western Siberia) and Shestopalov et al.. (2006) confirmed that these viruses were related to those isolated from migratory birds at Qinghai Lake described by Chen et al..2 (2006a), A/grebe/Novosibirsk/29/05 viruses, and A/chicken/Nigeria/641/06. These two last viruses were designated as 'Qinghai-like' virus by Smith et al.. (2006). A study that reported the first H5N1 outbreak in Czech Republic showed the same results (Nagy et al., 2006). Our phylogenetic analyses revealed that HA and NA genes of French viruses also clustered with those of the 20052006 H5N1 viruses from western Asia and notably with viruses from Qinghai Lake, Middle East, Europe and Africa, and belonged to the recently defined phylogenetic H5 
clade 2 subclade 2 (WHO, 2007). Russian and Czech works did not conclude definitively on the origin of viruses characterised in their country. According to Shestopalov et al. . (2006), wild birds that migrated in the spring from south eastern Asia might have introduced the virus in western Siberia located on this flyway. Nagy et al.2. (2006) showed that the Czech strains were in close relationship with viruses identified in Italy (A/mallard/Italy/835/06), Turkey and Egypt, and suggested that the virus may have spread from the south east through Italy or the Balkans to Bavaria and Austria, and then to Czech Republic.

Although the French viruses were very similar, phylogenetic analyses revealed the presence of two related but distinct HPAI H5N1 genetic subgroups in winter 2006, suggesting two separate introductions at the same time in the same area. Taking into account the very low reading error rate of the DNA polymerase enzyme used to perform PCRs $\left(1.8 \times 10^{-6}\right)$, the divergences observed in several sequences for a same nucleotide position were significant and probably not artefacts. In addition, we showed that the index case virus was not the source of the turkey outbreak but a virus belonging to the second genetic subgroup which clustered viruses detected during the 2 months period of the epizooty in wild birds in France. These viruses did not display any significant nucleotide variation, indicating that genetic difference between the two subgroups did not correspond to either geographical origin or temporal evolution. The case described in France and in eastern neighbouring countries in early 2006 occurred after unusual westward waterfowl movements that were associated with a spell of cold weather in eastern Europe and notably in the Black Sea area where H5N1 virus had been enzootic Deleted: was since autumn 2005 (Gilbert et al., 2006). This hypothesis was also shared by Weber $e t$ $a l_{.2}$ (2007) who recently published results on the molecular analysis of H5N1 HPAI viruses isolated from wild birds and mammals in the far north of Germany. They 
confirmed the close relationship of these German viruses with those from western

Siberia. In any case, our results revealed that at least two viral introductions occurred

into Italy and into Germany (notably into Bavaria). More recently, several other

Bavarian HA and NA sequences have become available in databases (accession numbers EF165048 to EF065066, and EF165571 to EF065588, respectively). Most of them were highly similar to A/mallard/Bavaria/1/2006 and two of them were close to A/common buzzard/Bavaria/2/2006. The authors confirmed the presence of two genetic groups in Bavaria (Rinder et al., 2007).

Surprisingly, the three French viruses that belonged to the first genetic subgroup retained the HA0 cleavage site motif PQGERKRKKR/G, which is unique to the sequences analysed in the present study. BLAST search confirmed that this cleavage site is also unique among the known HPAI H5N1 viruses, notably the Bavarian ones. We revealed initially the presence of two index case viral RNA populations in the effluent fluid from the original clinical swab (Accession number AM231714), but when we amplified the virus into eggs, we selected the viral population showing the mutation R342K into the cleavage site (Accession number AM498617). However, for the two other cases and prior viral amplification, we exclusively characterised the viral population showing the mutation. These viruses were not detected after mid-April 2006 although active surveillance was carried out in this area.

\section{Acknowledgments}

The authors wish to acknowledge the excellent technical support provided by Josiane Lamandé, Chantal Allée, Katell Ogor, Cécile Guillou-Cloarec and Céline Macé. The
} 
authors are grateful to the ONCFS for sample collecting and for sending to veterinary laboratories, and to the Departmental Veterinary Laboratories of Ain for screening positive samples by using M-based RT-PCR.

\section{References}

Alexander, D.J. (2005). Chapter 2.07.12 Avian Influenza. Manual for diagnostic tests and

Formatted: Block Text, Indent: Left: $-28.35 \mathrm{pt}$, Hanging: $28.35 \mathrm{pt}$ vaccines for terrestrial animals 5th edition. World Organisation for Animal Health, Paris, France. http://www.oie.int/eng/normes/MMANUAL/A 00037.htm, Chen, H., Smith, G.J.D., Zhang, S.Y., Qin, K., Wang, J., Li, K.S., Webster, R.G., Peiris, Deleted: II Formatted: Left, Indent: Hanging: $28.35 \mathrm{pt}$ J.S.M. \& Guan, Y. (2005). H5N1 virus outbreak in migratory waterfowl. Nature, 436, $191-192$

Chen, H., Li, Y., Li, Z., Shi, J., Shinya, K., Deng, G., Qi, Q., Tian, G., Fan, S., Zhao, H.,

Sun, Y. \& Kawaoka, Y. (2006a). Properties and dissemination of H5N1 viruses isolated during an Influenza outbreak in migratory waterfowl in western China. Journal of Virology, 80, 5976-5983. Deleted: II

Ghen, H., Smith, G.J.D., Li, K.S., Wang, J., Fan, X.F., Rayner, J.M., Vijaykrishna, D., Hanging: $28.35 \mathrm{pt}$ Zhang, J.X., Zhang, L.J., Guo, C.T., Cheung, C.L., Xu, K.M., Duan, L., Huang, K., Qin, K., Leung, Y.H., Wu, W.L., Lu, H.R., Chen, Y., Xia, N.S., Naipospos, T.S., Yuen, K.Y., Hassan, S.S., Bahri, S., Nguyen, T.D., Webster, R.G., Peiris, J.S. \& Guan, Y. (2006b). Establishment of multiple sublineages of H5N1 influenza virus in Asia: implications for pandemic control. Proceedings of National Academy of Sciences of the USA, 103, 2845-2850, 
Ghen, H., Smith, G.J.D., Zhang, S.Y., Qin, K., Wang, J., Li, K.S. \& Webster, R.G. (2006c).

H5N1 virus outbreak in migratory waterfowl. Nature, 436, 191.

Ellis, T.M. Bousfield, R.B., Bissett, L.A., Dyrting, K.C., Luk, G.S.M., Guan, Y., Tsim,

S.T., Sturm-Raminez, K., Webster, R.G., Guan, Y. \& Peiris, J.S.M. (2004).

Investigation in outbreaks of highly pathogenic H5N1 avian influenza in waterfowl

and wild birds in Hong Kong in late 2002. Avian Pathology, 33, 492-505.

Felsenstein, J. (2002). PHYLIP (Phylogeny Inference Package), version 3.6. Department of

Genome Sciences, University of Washington, Seattle, USA.

Fouchier, R., Schneeberger, P., Rzendaal, F., Broekman, J., Kemink, S., Munster, V.,

Kuiken, T., Rimmelzwaan, G., Schutten, M., van Doornum, G., Guus, K., Arnold, B.,

Marion, K. \& Osterhaus, A.D.M.E. (2004). Avian influenza A virus (H7N7)

associated with human conjunctivitis and a fatal case of acute respiratory distress

syndrome. Proceedings of National Academy of Sciences of the USA, 101, 1356-1361

Gilbert, M., Xiao, X., Domenech, J., Lubroth, J., Martin, V. \& Slingenbergh, J. (2006).

Anatidae migration in the western Palaearctic and spread of highly pathogenic avian

influenza H5N1 virus. Emerging Infectious Diseases, 12, 1650-1656.

Guan, Y., Peiris, J.S., Lipatov, A.S., Ellis, T.M., Dyrting, K.C., Krauss, S., Zhang, L. J.,

Webster, R.G. \& Shortridge, K.F. (2002). Emergence of multiple genotypes of H5N1

avian influenza viruses in Hong Kong SAR. Proceedings of National Academy of

Sciences of the USA, 99, 8950-8955.

Ha, Y., Stevens, D.J., Skehel, J.J. \& Wiley, D.C. (2001). X-ray structures of H5 avian and

H9 swine influenza virus hemagglutinins bond to avian and human receptor analogs.

Proceedings of National Academy of Sciences of the USA, 98, 11181-11186.

Hatta, M., Gao, P., Halfmann, P. \& Kawaoka Y. (2001). Molecular basis for high virulence

of Hong Kong H5N1 influenza A viruses. Science, 293, 1840-1842.
Formatted: Normal, Indent:

Hanging: 28.35 pt, Right: -6.8 pt

Deleted: II

Formatted: Body Text, Indent: Hanging: 28.35 pt, Right: 0 pt
Deleted: II

Deleted: II

Formatted: Block Text, Indent: Left:

-28.35 pt, Hanging: 28.35 pt, Right:

$0 \mathrm{pt}$
Deleted: $\mathbb{I}$

Formatted: Left, Indent: Hanging: $28.35 \mathrm{pt}$

Deleted: II

Deleted: II 
Keawcharoen, J., Oraveerakul, K., Kuiken, T., Fouchier, R.A., Amonsin, A., Payungporn,

S., Noppornpanth, S., Wattanodorn, S., Theambooniers, A., Tantilertcharoen, R., Pattanarangsan, R., Arya, N., Ratanakorn, P., Osterhaus, D.M. \& Poovorawan, Y.

(2004). Avian influenza H5N1 in tigers and leopards. Emerging Infectious Diseases, $10,2189-2191$

Kishida, N., Sakoda, Y., Isoda, N., Matsuda, K., Eto, M., Sunaga, Y., Umemura, T. \&

Deleted: II Formatted: Body Text 2, Indent: Hanging: $28.35 \mathrm{pt}$, Right: $0 \mathrm{pt}$

Kida, H. (2005). Pathogenicity of H5 influenza viruses for ducks. Archives of Virology, 150, 1383-1392.

Kuiken, T., Rimmelzwaan, G., Van Riel, D., Van Amerongen, G., Baars, M., Fouchier, R. \& Osterhaus, A. (2004). Avian H5N1 influenza in cats. Science, 306, 241.

Deleted: $\mathbb{I}$

Formatted: Left, Indent: Hanging: $28.35 \mathrm{pt}$

Deleted: II

Kumar, S., Tamura, K. \& Nei, M. (2004). MEGA3: Integrated software for molecular evolutionary genetics analysis and sequence alignment. Briefings in Bioformatics, 5, $150-163$

Le Gall-Reculé, G., Schmitz, A., Massin, P., Cherbonnel, M., Lamandé, J., Allée, C., Ogor, K., Toquin, D., Rivallan, G., Zwingelstein, F., Picault, J-P., Eterradossi, N., Guionie, O., Briand, F-X. \& Jestin, V. (2006). Molecular characterisation of highly pathogenic avian Influenza H5N1 in France collected early 2006. In A. Leitão \& C. Martins (Eds.). Proceedings of the $7^{\text {th }}$ International Congress of Veterinary Virology (p. 132). Lisboa, Portugal.

Li, Z., Chen, H., Jiao, P., Deng, G., Tian, G., Li, Y., Hoffmann, E., Webster, R.G., Matsuoka, Y. \& Yu, K. (2005). Molecular basis of replication of duck H5N1 influenza viruses in a mammalian model. Journal of Virology, 79, 12058-12064.

Li, K.S., Guan, Y., Wang, J., Smith, G.J.D., Xu, K.M., Duan, L., Rahardjo, A.P., Puthavathana, P. Buranathai, C., Nguyen, T.D., Estoepangestie, A.T., Chaisingh, A., Auewarakul, P., Long, H.T., Hanh, N.T., Webby, R.J., Poon, L.L., Chen, H., 
Shortridge, K.F., Yuen, K.Y., Webster, R.G. \& Peiris, J.S. (2004). Genesis of a highly pathogenic and potentially pandemic H5N1 influenza virus in eastern Asia. Nature, $430,209-213$

Li, Z., Jiang, Y., Jiao, P., Wang, A., Zhao, F., Tian, G., Wang, X., Yu, K., Bu, Z. \& Chen, H. (2006). The NS1 gene contributes to the virulence of H5N1 avian influenza viruses. Journal of Virology, 80, 11115-11123, Deleted: $\mathbb{I}$

Liu, J., Xiao, H., Lei, F., Zhu, Q., Qin, K., Zhang, X.W., Zhang, X.L., Zhao, D., Wang, G., Feng, Y., Ma, J., Liu, W., Wang, J. \& Gao, G.F. (2005). Highly pathogenic H5N1 influenza virus infection in migratory birds. Science, 309, 1206 Macken, C., Lu, H., Goodman, J. \& Boykin, L. (2001). The value of a database in surveillance and vaccine selection, in Options for the Control of Influenza IV.

A.D.M.E. Osterhaus, N. Cox \& A.W. Hampson (Eds.), Amsterdam: Elsevier Science, pp.103-106

Mase, M., Tsukamoto, K., Imada, T., Imai, K., Tanimura, N., Nakamura, K., Yamamoto, Y., Hitomi, T., Kira, T., Nakai, T., Kiso, M., Horimoto, T., Kawaoka, Y. \& Yamaguchi S. (2005). Characterization of H5N1 influenza A viruses isolated during the 2003-2004 influenza outbreaks in Japan. Virology, 332, 167-176.

Deleted: II Nagy, A., Machova, J., Hornickova, J., Tomci, M., Nagl, I., Horyna, B. \& Holko, I. (2006).

Highly pathogenic avian influenza virus subtype H5N1 in mute swans in Czech

Republic. Veterinary Microbiology, 120, 9-16. Deleted: II

QIE, Update on Avian Influenza [on line] (2006a).

http://www.oie.int/downld/AVIAN\%20INFLUENZA/a_AI-Asia.htm

фIE, Disease Information [on line] (2006b). http://www.oie.int/eng/info/hebdo/AIS_30.htm,

Deleted: II

фIE, Disease Information [on line] (2006c). http://www.oie.int/eng/info/hebdo/AIS_29.htm、

Deleted: II 
Peiris, J.S., Yu, W.C., Leung, C.W., Cheung, C.Y., Ng, W.F., Nicholls, J.M., Ng, T.K., Chan, K.H., Lai, ST, Lim, WL, Yuen, KY \& Guan, Y. (2004). Re-emergence of fatal human influenza A subtype H5N1 disease. Lancet, 363, 617-619.

Perdue, M.L. \& Suarez D.L. (2000). Structural features of the avian influenza virus hemagglutinin that influence virulence. Veterinary Microbiology, 74, 77-86.

Rinder, M., Lang, V., Fuchs, C., Hafner-Marx, A., Bogner, K-H., Neubauer, A., Büttner, M. \& Rinder, H. (2007). Genetic evidence for multi-envent imports of avian influenza virus A (H5N1) into Bavaria, Germany. Journal of Veterinary Diagnostic Investigation, 19, 279-282.

Scholtissek, C., Rhohde, W., von Hoyningen, V., \& Rott, R. (1998). On the origin of the human influenza virus subtypes H2N2 and H3N2. Virology, 87, 13-20. Seo, S.H., Hoffmann, E. \& Webster, R.G. (2002). Lethal H5N1 influenza viruses escape host anti-viral cytokine responses. Nature Medicine, 8, 950-954.

Deleted: II

Formatted: Style3, Indent: Hanging: $28.35 \mathrm{pt}$

Deleted: II

Formatted: Left, Indent: Hanging: $28.35 \mathrm{pt}$

Deleted: II

Deleted: II

Formatted: Normal, Indent: Hanging: $28.35 \mathrm{pt}$

Shinya, K., Hamm, S., Hatta, M., Ito, H., Ito, T. \& Kawaoka, Y. (2004). PB2 amino acid at position 627 affects replicative efficiency, but not cell tropism, of Hong Kong H5N1 influenza A viruses in mice. Virology, 15, 258-66. Smith, G.J.D., Fan, X.H., Wang, J., Li, K.S., Qin, K., Zhang, J.X., Vijaykrishna, D., Deleted: $\mathbb{q}$ $28.35 \mathrm{pt}$, Right: $-6.8 \mathrm{pt}$

Cheung, C.L., Huang, K., Rayner, J.M., Peiris, J.S.M., Chen, H., Webster, R.G. \&

Guan, Y. (2006). Emergence and predominance of an H5N1 influenza variant in

China. Proceedings of National Academy of Sciences of the USA, 103, 16936-16941 
Sturm-Ramirez, K. M., Ellis, T., Bousfield, B., Bissett, L., Dyrting, K., Jehg, J.E., Poon,

L., Guan, Y., Peiris, M. \& Webste,r R.G. (2004). Reemerging H5N1 influenza A

viruses in Hong Kong in 2002 are highly pathogenic to ducks. Journal of Virology,

78, 4892-4901

Thompson, J.D., Higgins, D.G. \& Gibson, T.J. (1994). CLUSTAL W: improving the

Deleted: II

Formatted: Left, Indent: Hanging: $28.35 \mathrm{pt}$

sensitivity of progressive multiple sequence alignment through sequence weighting,

positions-specific gap penalties and weight matrix choice. Nucleic Acids Research, 22,

$4673-4680$

Tran, T.H., Nguyen, T.L., Nguyen, T. D., Luong, T.S., Pham, P.M., Nguyen, V.C., Pham,

Deleted: II

Formatted: Body Text 2, Indent: Hanging: $28.35 \mathrm{pt}$

T.S., Vo, C.D. Le, T.Q., Ngo, T.T., Dao, B.K., Le, P.P., Nguyen, T.T., Hoang, T.L.,

Cao, V.T., Le, T.G., Nguyen, D.T., Le, H.N., Nguyen, K.T., Le, H.S., Le, V.T.,

Christiane, D., Tran, T.T., Menno de, J., Schultsz, C., Cheng, P., Lim, W., Horby, P.

\& Farrar, J. (2004). World Health Organization International Avian Influenza

Investigative Team, Avian influenza A (H5N1) in 10 patients in Vietnam. New

England Journal of Medicine, 350, 1179-1188.

Deleted: II

Formatted: Left, Indent: Hanging:

Weber, S., Harder, T., Starick, E., Beer, M., Werner, O., Hoffmann, B., Mettenleiter, T. C. $28.35 \mathrm{pt}$

\& Mundt, E. (2007). Molecular analysis of highly pathogenic avian influenza virus of subtype H5N1 isolated from wild birds and mammals in northern Germany. Journal of General Virology, 88, 554-558.

Deleted: II

Webster, R.G., Guan, Y., Peiris, M., Walker, D., Krauss, S., Zhou, N.N., Govorkova, E.A., Ellis, T.M., Dyrting, K.C., Sit, T., Perez, D.R. \& Shortridge, K.F. (2002).

Characterization of $\mathrm{H} 5 \mathrm{~N} 1$ influenza viruses that continue to circulate in geese en southeastern China. Journal of Virology, 76, 118-126.

Deleted: II

Webster, R.G., Peiris, M., Chen, H. \& Guan Y. (2006). H5N1 outbreaks and enzootic

influenza. Emerging Infectious Diseases, 12, 3-8,

Deleted: II 
WHO. Epidemic and Pandemic Alert and Response (EPR). Antigenic and genetic characteristics of $\mathrm{H} 5 \mathrm{~N} 1$ viruses and candidate $\mathrm{H} 5 \mathrm{~N} 1$ vaccine viruses developed for potential use as pre-pandemic vaccines [on line] (2007).

http:/www.who.int/crs/disease/avian_influenza/guidelines/h5n1 virus/en/index.html

Xu, X., Subbarao, K., Cox, N.J. \& Guo, Y. (1999). Genetic characterization of the pathogenic influenza A/Goose/Guangdong/1/96(H5N1) virus: similarity of its hemagglutinin gene to those of H5N1 viruses from the 1997 outbreaks in Hong Kong. Virology, 216,15-19. 


\section{Figure legends}

Figure 1. Geographical location of the H5N1 HPAIV outbreaks in France, number of

Formatted: Font: Italic outbreak, period, species involved and number of dead birds. The map shows the

French departments and those where viruses were identified are shaded in grey.

Figure 2. Phylogenetic tree showing the genetic relationships between representative

Formatted: Font: Italic highly pathogenic H5N1 avian influenza A viruses and the 12 studied French isolates for the PB1 gene (nucleotides 84-265; the tree was rooted to A/duck/Hong Kong/Y280/97(H9N2) virus). Numbers above branches indicate bootstrap values from 1,000 replicates (only values over $75 \%$ are show). Genotypes are labelled * according to Chen et al. (2005); ** according to Smith et al. (2006).

Formatted: Font: Italic Formatted: Font: Italic

Figure 3. Phylogenetic relationships of the haemagglutinin gene of representative

Formatted: Font: Italic highly pathogenic H5N1 avian influenza A viruses and the six studied French isolates.

Analysis was based on nucleotides 77-1631 and the tree was rooted to

A/mallard/Denmark/64650/03(H5N7) virus. Numbers above branches indicate

bootstrap values from 1,000 replicates (only values over $75 \%$ are show). Genotypes

are labelled. *, according to Smith et al. (2006).

Formatted: Font: Italic 
Figure 1. Geographical localisation of the H5N1 HPAIV outbreaks areas in France, number of outbreak, period, species involved and number of dead bird. The map shows the French departments and those where viruses were identified are visualised in grey.

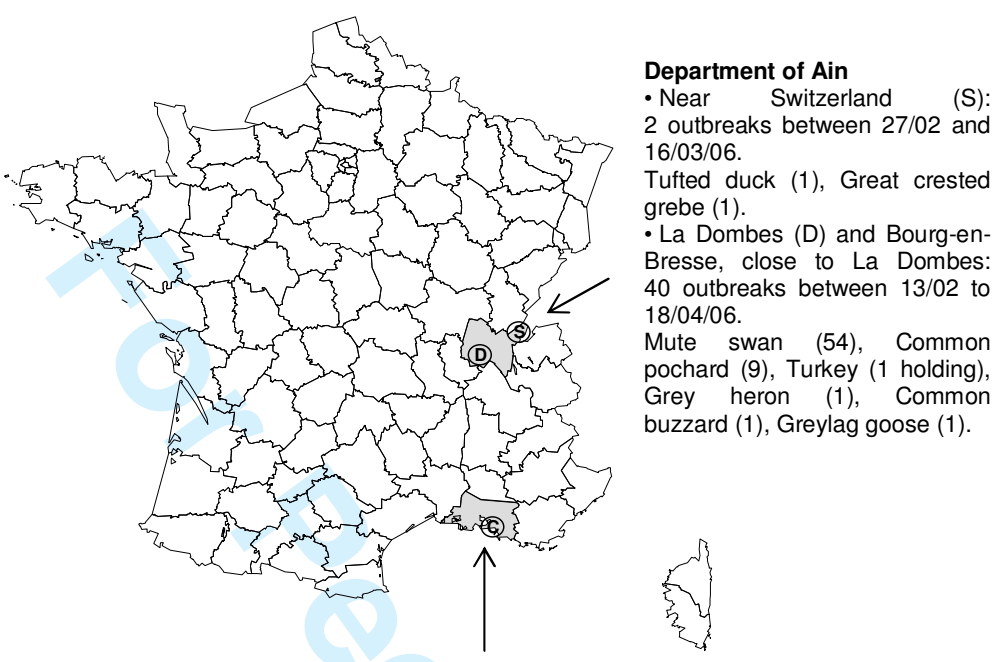

Department of Bouches-du-Rhône, Camargue (C): one outbreak on 28/02/06. Mute swan (1). 
Table 1. French H5N1 HPAI viruses studied in this work

Formatted: Font: Italic

\begin{tabular}{|c|c|c|c|c|}
\hline Virus $^{\mathrm{a}}$ & Species & Department (Area $\left.{ }^{\mathrm{b}}\right)$ & Date & Name \\
\hline $06167-2.1$ & Common pochard & Ain (D) & $16 / 02 / 06$ & A/common pochard/France/ 96167 \\
\hline $06222-1.1$ & Turkey & Ain (D) & $23 / 02 / 06$ & $\mathrm{~A} /$ turkey/France/06222-1.1/2006 \\
\hline 06299 & Mute swan & Ain (D) & $24 / 02 / 06$ & $\mathrm{~A} /$ mute swan/France/06299/2006 \\
\hline 06303 & Mute swan & Ain (D) & $28 / 02 / 06$ & $\mathrm{~A} / \mathrm{mute}$ swan/France/06303/2006 \\
\hline $06254 \mathrm{a}$ & Mute swan & Bouches-du-Rhône $(\bar{C})$ & $04 / 03 / 06$ & $\mathrm{~A} /$ mute swan/France/06254a/2006 \\
\hline 06256 & Tufted duck & Ain $(S)$ & 04/03/06 & A/tufted duck/France/06256/2006 \\
\hline 06310 & Greylag goose & Ain (D) & $07 / 03 / 06$ & A/greylag goose/France $/ 06310 / 2$ \\
\hline $06292 \mathrm{a}$ & Common pochard & Ain (D) & $11 / 03 / 06$ & $\mathrm{~A} /$ common pochard/France/96292 \\
\hline $06631 \mathrm{a}$ & Mute swan & Ain (D) & $11 / 03 / 06$ & $\mathrm{~A} /$ mute swan/France/06631a/2006 \\
\hline $0 \overline{6} 314$ & Mute swan & Ain (D) & $14 / 03 / 06$ & $\mathrm{~A} /$ mute swan/France/06314/2006 \\
\hline 06348a & Great crested grebe & $\operatorname{Ain}(\mathrm{S})$ & $19 / 03 / 06$ & A/great crested grebe/France/0634 \\
\hline 06484b & Mute swan & Ain (D) & $18 / 04 / 06$ & $\mathrm{~A} /$ mute swan/France/06484b/20c \\
\hline
\end{tabular}

${ }^{a}$ Six strains (in bold) were amplified in SPF chicken eggs (one or two passages) and for 4 which the entire HA and 70\% NA sequences were established.

$\mid{ }^{\mathrm{b}}$ areas in France where viruses were found with abbreviations as reported in Figure 1:

(D) La Dombes, (S) near Switzerland, (C) Camargue

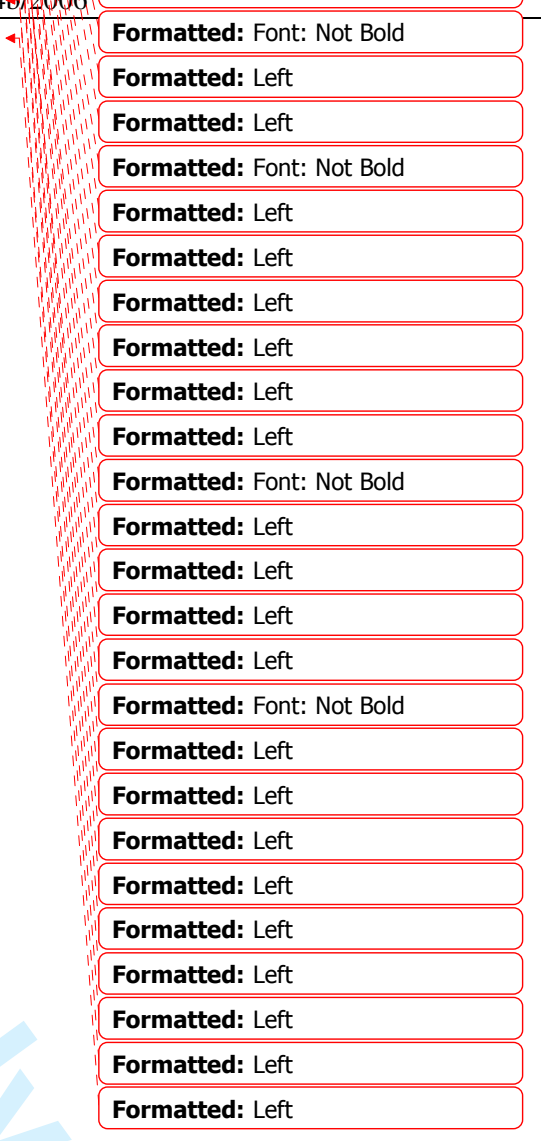


Table 2. Comparison of amino acid sequences of different gene segments of twelve French $H 5 N 1 \bar{H} \bar{P} \bar{I}$ viruses and characterisation of amino acids at specific positions.

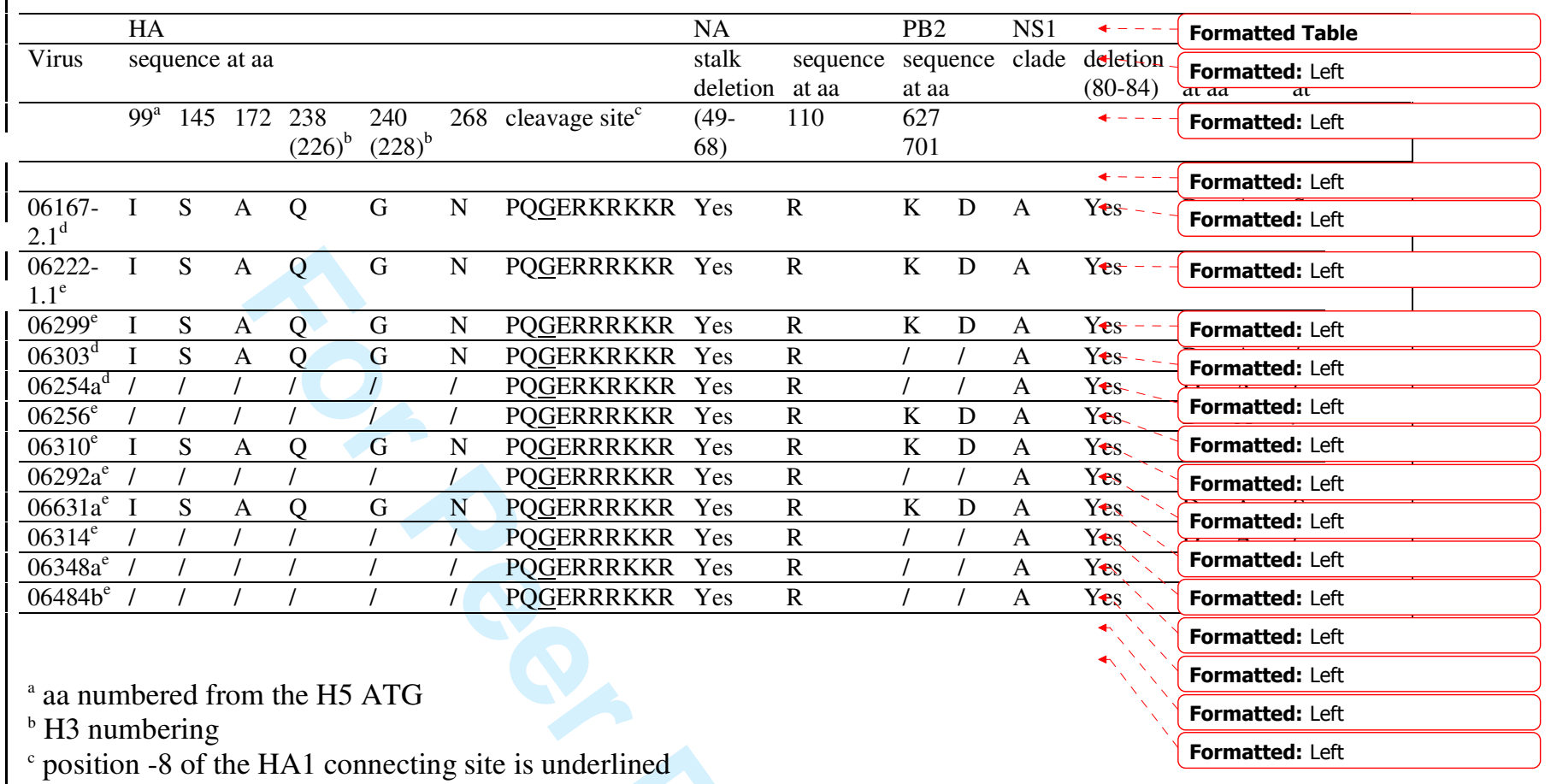

d viruses belonging to the index virus subgroup, according to phylogenetic results

${ }^{\mathrm{e}}$ viruses belonging to the other subgroup, according to phylogenetic results

${ }^{\mathrm{f}}$ data not available 


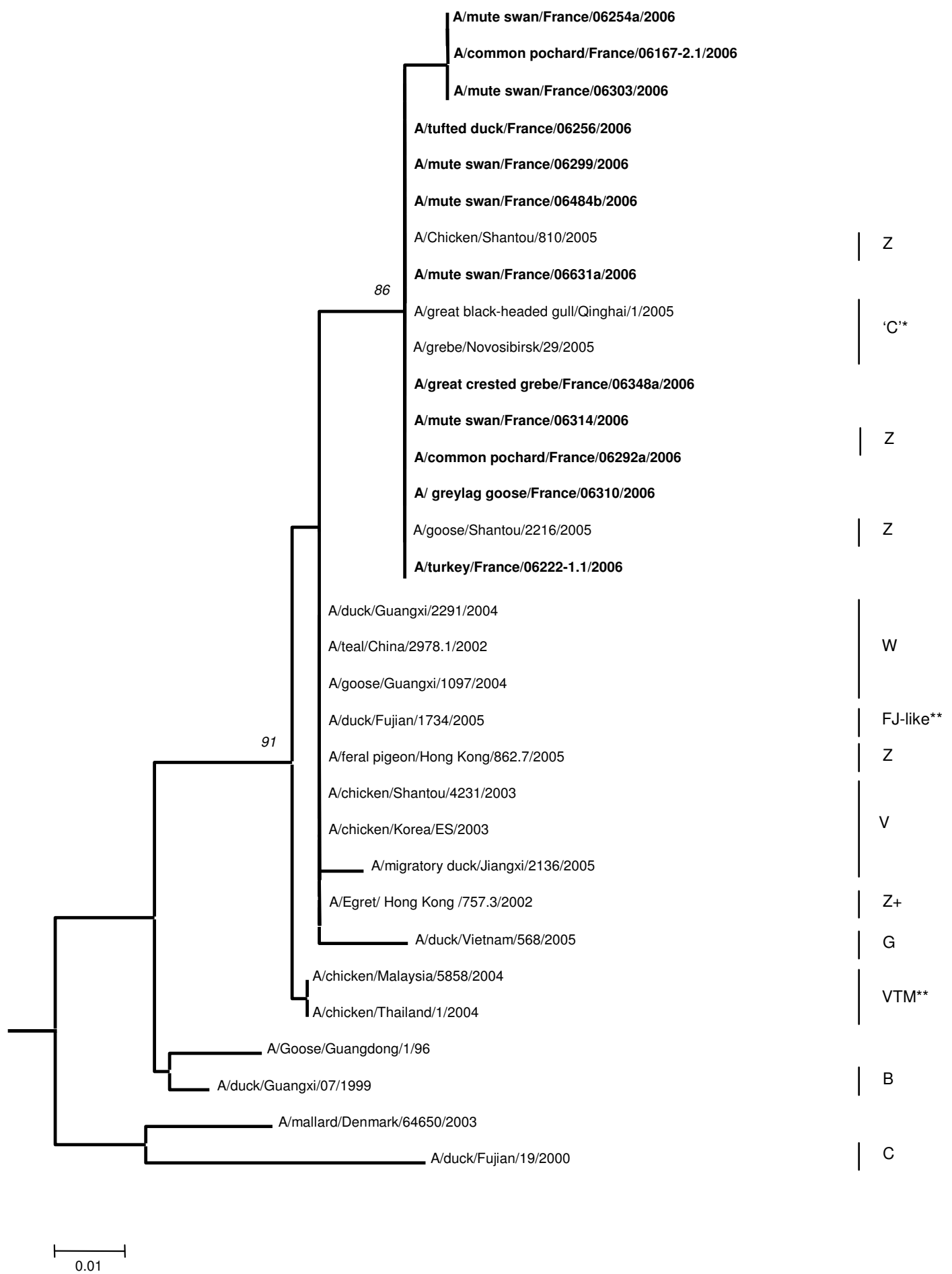

Figure 2. 


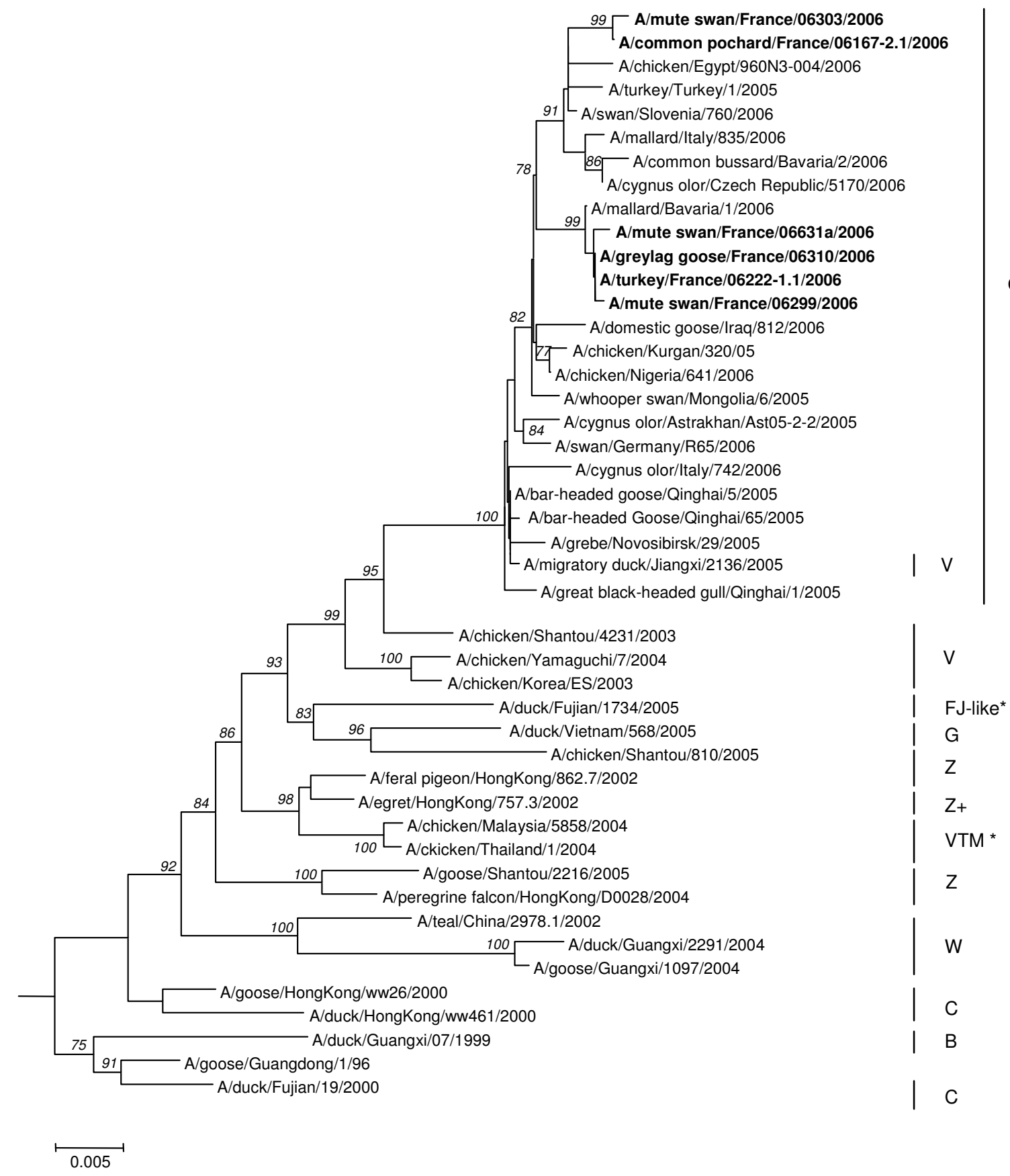

Figure 3. 